\title{
Malignant Melanoma of the Eye- A Case Report
}

\author{
Dr.Vanlalruati Fanai ${ }^{1}$, Dr.Y.Chingsuingamba Meitei ${ }^{2}$, \\ Dr. Laishram Usharani ${ }^{3}$,Dr.Kasomhung Soreingam ${ }^{4}$,Dr.Catherine Lalmuankimi ${ }^{5}$ \\ 1,2,3, (Department of ophthalmology, Regional institute of medical sciences, Imphal,India) \\ ${ }^{4}$ (Department of Anaesthesia, Regional Institute Of Medical Sciences,Imphal,India) \\ ${ }^{5}$ (Department of Radiotherapy, Regional Institute Of Medical Sciences)
}

\begin{abstract}
We describe a 85 year old, male patient who attended our OPD with profused swelling of the left eye associated with loss of vision for the past 4 months. He gave no history of trauma, no history of fever and swelling is not associated with pain. The mass was profusedly large measuring $40 \mathrm{~cm} \times 30 \mathrm{~cm}$ (approx), there was multiple, non-tender, firm, irregular cauliflower like growth which bleeds on touch filled the whole globe. Anterior and posterior segment cannot be visualized. The patient came at the last stage,so we could not perform Ultrasonography and ophthalmoscopic examinations. Histopathological examination and CT scan of the orbit was done and we diagnosed it as a case of uveal melanoma of the left eye. 200 centigray/day $\times 20$ fractions of external beam radiotherapy was given for 20 days, the tumour size markedly decreased after treatment. The case was studied in detail as the condition is rarely seen in the north eastern part of India.
\end{abstract}

Keywords: CT orbit, External beam radiotherapy, Histopathology,Proptosis, Uveal Melanoma.

\section{Introduction}

Ocular melanoma is a rare type of tumour and the exact cause is unknown. A 85 year old male attended our OPD with profused swelling of the left eye associated with loss of vision for the past 4 months. He gave no history of trauma, no history of fever and swelling is not associated with pain. The mass was profusedly large measuring $40 \mathrm{~mm} \times 30 \mathrm{~mm}$ (approx), there was multiple, non-tender, firm, irregular cauliflower like growth which bleeds on touch filled the whole globe. This case has been reported as malignant melanoma is rarely found in the north-eastern part of India.

\section{EXAMINATION OF LEFT EYE :}

\section{Ophthalmologic Examinations}

- External adnexa with eyelid shows ecchymosis, erythema and tense upper eyelid.

- Proptosis of the eyeball was eccentric.

- Proptosis measurement was done with Twin Luedde's transparent exophthalmometer and found 38 $\mathrm{mm}$ on $\mathrm{L} / \mathrm{E}$ compared to $15 \mathrm{~mm}$ on $\mathrm{R} / \mathrm{E}$.

- Visual acuity-no perception of light.

- Multiple,non-tender,firm,irregular cauliflower like growth which bleeds on touch filled the whole globe.

- Anterior and posterior segment cannot be visualized.

-Hb-7.0 gm./dl, ESR-105 mm/1st hr.

\section{Investigations}

-TLC, DLC, Platelet count, blood sugar, LFT,KFT, Sr. electrolyte, LDH, HBs-Ag,HIV, HCV-Ab tests were found normal.

-ECG,Chest X-ray were WNL.

-Bone marrow examination shows no evidence of metastasis or granuloma seen.

FNAC - FNAC of the swelling was done 


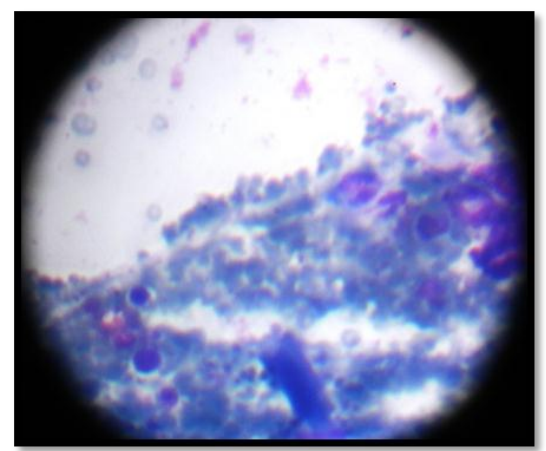

Fig 1 : Smears shows clusters of round to polygonal cells having abundant cytoplasm and hyperchromatic pleomorphic central nucliei with coarse chromatin pattern and prominent nucleoli. A few large cells having round to triangular nuclei and tumour giant cells are also seen. Features

\section{CT- Orbit} suggestive of melanoma.

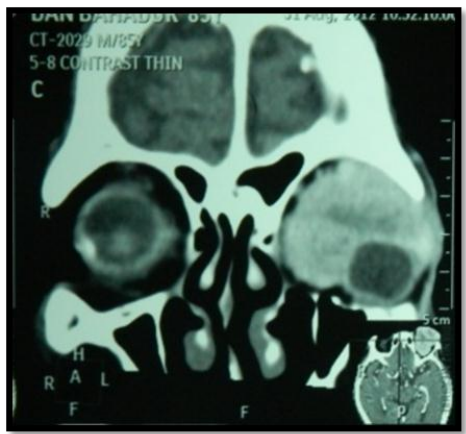

Fig 2 : Large enhancing left orbital mass, extraconal,predominantly retrobulbar,extending anteriorly to superior orbit, displacing the eyeball anteriorly and inferior laterally and optic nerve laterally with involvement of extraocular muscles suggestive of Melanoma.

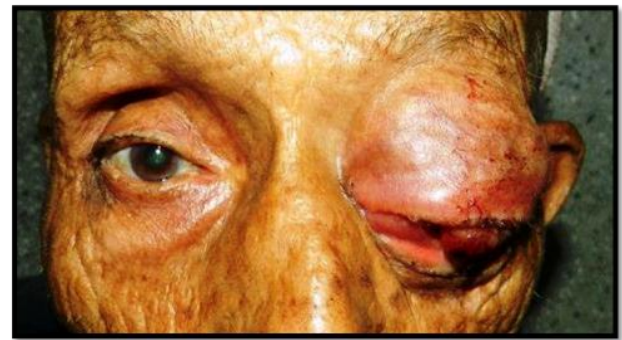

Fig 3: AT THE TIME OF PRESENTATION

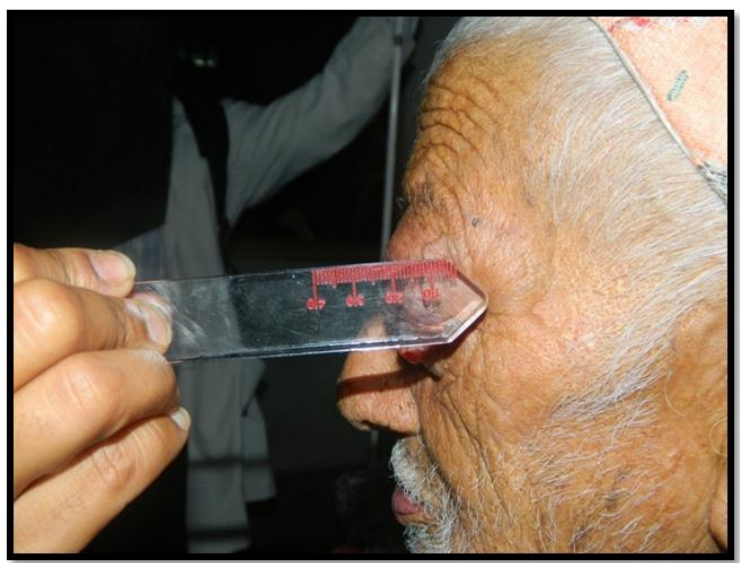

Fig 4 : AFTER TREATMENT 


\section{Discussions}

Melanoma is a very aggresive type of cancer that can spread rapidly. The outcome of the melanoma of the eye depends on the size of cancer at the time of diagnosis. Most patients will survive atleast 5 years from the time of diagnosis if the cancer has not spread outside the eye. If the cancer has spread outside the eye, the chance of survival is much lower. A number of different treatments are used for ocular melanoma. The treatment depends on the size, cell type and position of the tumour, and on other factors, such as general health and level of vision in both eyes. The aim of treatment is to destroy the cancer cells. Treatment modality includes photocoagulation, transpupillary thermotherapy (TTT), radiatiotherapy, local excision or enucleation.

\section{Conclusion}

Melanoma is a malignant tumour that most often arises in the skin, less commonly found in the eye and other sites in the body. It affects about 6 people per million population per year. Melanoma of the eye typically occurs in fair skinned, blue or green eyed men and women. It is relatively rare in Indias. This case highlights the need of timely referral to an Ophthalmologist which is a difficult scenario in the Northeastern part of India due to ignorant and unawareness of the common people.

\section{References}

[1] OcularMelanoma.UpToDate. www.uptodate.com (accessed march 2013).

[2] Raghavan et al. Cancer: Principles and Practice of Oncology. 7th ed. 2005. Lippincott Williams and Wilkins.

[3] Raghavan et al. The Textbook of Uncommon Cancers. 3rd ed. 2006. Wiley.

[4] Singh et al. Clinical Opthalmic Oncology. 2007. 1st edition. Saunders Elsevier.

[5] Souhami, Tobias. Cancer and its Management. 5th ed. 2005. Oxford Blackwell. 